Commentary

\title{
A Third Wave of Selective Exposure Research? The Challenges Posed by Hyperpartisan News on Social Media
}

\author{
Matthew Barnidge ${ }^{1, *}$ and Cynthia Peacock ${ }^{2}$ \\ ${ }^{1}$ Department of Journalism \& Creative Media, The University of Alabama, Tuscaloosa, AL 35487, USA; \\ E-Mail: mhbarnidge@ua.edu \\ 2 Department of Communication Studies, The University of Alabama, Tuscaloosa, AL 35487, USA; E-Mail: cpeacock@ua.edu \\ * Corresponding author
}

Submitted: 1 June 2019 | Accepted: 3 June 2019 | Published: 30 July 2019

\begin{abstract}
Hyperpartisan news on social media presents new challenges for selective exposure theory. These challenges are substantial enough to usher in a new era-a third wave- of selective exposure research. In this essay, we trace the history of the first two waves of research in order to better understand the current situation. We then assess the implications of recent developments for selective exposure research.
\end{abstract}

\section{Keywords}

democracy; hyperpartisan news; political communication; populism; public sphere; selective exposure; social media

\section{Issue}

This commentary is part of the issue "Selective Exposure in a Changing Political and Media Environment", edited by María Luisa Humanes (University Rey Juan Carlos, Spain).

(C) 2019 by the authors; licensee Cogitatio (Lisbon, Portugal). This article is licensed under a Creative Commons Attribution 4.0 International License (CC BY).

\section{Introduction}

Hyperpartisan news on social media presents new challenges for selective exposure theory. These challenges are substantial enough to usher in a new era-a third wave-of selective exposure research. In this essay, we trace the history of the first two waves of research in order to better understand the current situation, paying particular attention to the societal factors that structure news exposure. This historical sketch focuses on the United States because that is where selective exposure research originated, but the trends we highlight are also applicable in other national contexts, and it is our assertion that hyperpartisan news affects political communication worldwide.

\section{The First Wave}

Selective exposure research can be traced back to the famous "People's Choice" study of the 1940 United States
Presidential Election (Lazarsfeld, Berelson, \& Gaudet, 1944), later forming the basis of the "minimal effects" paradigm of the 1950s and 1960s (Klapper, 1960). American society in the 1940s was characterized by "relatively dense memberships in a group-based society networked through political parties, churches, unions, and service organizations" (Bennett \& lyengar, 2008, p. 707). This dense, community-oriented social organization was accompanied by a rich local newspaper ecology: Most cities had more than one newspaper and many had niche papers that catered to specific communities. Radio was immensely popular, but television was not yet on the scene. Thus, the American mass media system was not yet fully formed, and most people relied heavily on their social networks and communities to stay informed about politics-a "two-step flow" of political communication.

Individuals' social networks therefore played a large role in structuring their exposure to news. People read particular newspapers because that's what people in their networks did. For many, selectivity was not nec- 
essarily a product of conscious political motivation, but rather a byproduct of their social surroundings. Scholars would later characterize this phenomenon as de facto selective exposure (Sears \& Freedman, 1967), which was arguably the most prominent conclusion drawn from first wave of research.

\section{The Second Wave}

Selective exposure research declined in popularity between the 1960s and the 2000s, at which point it was renewed with vigor in response to the rise of partisan media on cable news and the internet. In the interim, American society had changed dramatically. Dense, community-oriented social networks had given way to diffuse, ego-centric networks (Fischer, 1982). The national mass media system had consolidated and then diversified with the advent of digital media technologies. Local media, meanwhile, had begun to decline.

Therefore, the societal factors governing news exposure also had changed. Exposure was now structured much more by personal interest than it was in the past. Many people chose not to pay attention to the news at all (Prior, 2007), and the rest could now choose news that reflected their political ideologies and/or partisan identities (Stroud, 2011). While it is true that online communities also shaped news exposure, membership in these communities was driven by personal interest rather than by geography. These developments led to growing concerns about political polarization (Garrett \& Stroud, 2014), and, thus, the second wave of selective exposure research emphasized the deleterious effects of partisanship in the media and the public.

\section{The Third Wave?}

Social media in general, and hyperpartisan news in particular, pose new challenges to selective exposure theory, and we predict that these challenges will usher in a third wave of research as scholars attempt to meet them. Social media have restructured news exposure in two ways: by diversifying social connections and by facilitating the rise of hyperpartisan news.

\subsection{Diversification}

Social media have changed people's news use habits, but they have not created "filter bubbles" of likeminded content. The filter bubbles idea, which drew from older fears about "online echo chambers" and "cyberBalkanization," has become a popular narrative since Pariser's (2011) influential book and its accompanying Ted Talk, but empirical evidence tells a different story. In fact, most research shows that rather than acting as a homogenizing influence, social media diversify communication relative to other settings (Barnidge, 2017).

Part of why this occurs is because we are once again getting our news through our social networks.
Many social media users report that they don't seek out news because they believe the news will come to them (Toff \& Nielsen, 2018), and these patterns of behavior result in relatively high levels of incidental exposure to news on social media (Fletcher \& Nielsen, 2018). However, this reliance on social networks for news is not a return to the 1940s. We are no longer embedded in tight-knit, community-based networks. Rather, social networks are large, diffused, diverse, and organized around individuals. Thus, social media promote not informational selectivity, but rather informational diversity, because the social networks that drive news exposure also have diversified.

\subsection{Hyperpartisan News}

Social media also have facilitated the rise of hyperpartisan news. Hyperpartisan news: (1) has an obviously one-sided political agenda, which makes no effort to balance opposing views; (2) pushes anti-system messages that are critical of both mainstream media and establishment politics, often relying on misinformation to do so; and (3) relies heavily on social media as a platform for dissemination. Thus, hyperpartisan news can be situated squarely at the intersection of partisan and alternative news, and considerable overlap exists between hyperpartisan news and "fake" news (Mourão \& Robertson, 2019).

This conceptual location distinguishes hyperpartisan news from older forms of partisan news, because hyperpartisan news is not just partisan, but also alternative. As non-mainstream media that eschew journalistic norms and routines, alternative media typically challenge or subvert mainstream narratives and establishment politics. Recently, these media have found a larger audience on social media, which afford news organizations a free publishing platform and users the ability to share messages independently of legacy media.

\section{Implications for Selective Exposure Research}

These two trends - the diversification of news exposure and the proliferation of hyperpartisan news-present new challenges to selective exposure research. These include: (1) two-sided exposure on social media; (2) the nature of hyperpartisan news effects; and (3) the ineffectiveness of traditional "antidotes" to selective exposure.

First, exposure to hyperpartisan news is generally two-sided. Because hyperpartisan news is typically produced for and spread via social media, there also are increased opportunities for incidental exposure to it. In fact, our own research suggests that social media users, particularly strong partisans, are exposed to both left- and right-leaning hyperpartisan news on social media (Peacock, Hoewe, Panek, \& Willis, 2019). Therefore, while people still seek out congenial information and share it on social media, they are exposed to counterattitudinal hyperpartisan news through the very same 
channels. Thus, selective exposure research must come to terms with the fact that the same social media behaviors can expose people to hyperpartisan sources on both sides of the political spectrum.

Second, the nature of hyperpartisan news effects may differ from the effects of exposure to older forms of partisan news. Hyperpartisan news is meant to cause outrage, cue partisan emotions, and get clicks (i.e., make money). Cyrus Massoumi, who ran a conservative page called Truth Monitor along with a liberal page called Truth Examiner, described his content as "always inflammatory" and "excluding facts from the other side." He says his sites were meant to cater to "the lowest common denominator". Hyperpartisan news does just that: It provides low-quality news with the goal of making money from people's - in many cases misguided-anger and outrage.

What does consuming such content do to news consumers? No doubt it exacerbates political polarization, particularly affective polarization. But these polarizing effects are likely just the tip of the iceberg. Hyperpartisan sites commonly traffic in misinformation and conspiracy theories (Mourão \& Robertson, 2019), a practice that probably results in pervasive distrust in institutions and information among its audience. The threat of hyperpartisan news is therefore less about exacerbating leftright ideological divides and more about creating new political divides between those who support democratic political systems and those who want to undermine them. It isn't just about competing perspectives. It is about blending truth and untruth to subvert those perspectives altogether, diverting public conversations away from factbased arguments and positions.

A consistent diet of hyperpartisan news likely results in an audience that is angry, misinformed, highly distrustful of news media and political institutions, and eager to vote for non-establishment or anti-democratic political candidates. Therefore, in today's media environment, we should perhaps be concerned more about antidemocracy effects than we are about political polarization. Furthermore, because of the global reach of social media, hyperpartisan news has the potential to undermine news media and political democracy not just in the United States but around the world. Indeed, hyperpartisan news certainly appears to coincide with the rise of populist parties and candidates in countries including Hungary, Brazil, the Philippines, Italy, France, and the United Kingdom, among others.

Finally, the known "antidotes" to the polarizing effects of selective exposure may not work the same for hyperpartisan news. Exposure to counter-dispositional information has commonly been heralded as a way to counteract the influence of partisan media, reduce polarization, and increase tolerance. When it comes to hyperpartisan news, though, it is difficult to see how this "antidotal effect" would work. Is it reasonable to believe one could "balance" the content of conservative Truth Monitor by reading the liberal Truth Examiner? Both sites dis- seminate the same low-quality, conspiratorial content, meaning one might anticipate even fewer reasoned opinions and lower tolerance from a reader who visits both left- and right-leaning hyperpartisan sites. Thus, exposure to hyperpartisan news may be a different animal altogether from partisan news on cable television and more established online sites-and one that is decidedly more threatening to the foundations of democratic societies around the world.

\section{Conflict of Interests}

The authors declare no conflict of interests.

\section{References}

Barnidge, M. (2017). Exposure to political disagreement in social media versus face-to-face and anonymous online settings. Political Communication, 34(2), 302-321. https://doi.org/10.1080/10584609.2016. 1235639

Bennett, W. L., \& lyengar, S. (2008). A new era of minimal effects? The changing foundations of political communication. Journal of Communication, 58(4), 707-731. https://doi.org/10.1111/j.1460-2466. 2008.00410.x

Fischer, C. S. (1982). To dwell among friends: Personal networks in town and city. Chicago, IL: University of Chicago Press.

Fletcher, R., \& Nielsen, R. K. (2018). Are people incidentally exposed to news on social media? A comparative analysis. New Media \& Society, 20(7), 2450-2468. https://doi.org/10.1177/ 1461444817724170

Garrett, R. K., \& Stroud, N. J. (2014). Partisan paths to exposure diversity: Differences in pro- and counterattitudinal news consumption. Journal of Communication, 64(4), 680-701. https://doi.org/10.1111/jcom. 12105

Klapper, J. T. (1960). The effects of mass communication. New York, NY: Free Press.

Lazarsfeld, P. F., Berelson, B., \& Gaudet, H. (1944). The people's choice. Oxford: Duell, Sloan \& Pearce.

Mourão, R. R., \& Robertson, C. T. (2019). Fake news as discursive integration: An analysis of sites that publish false, misleading, hyperpartisan and sensational information. Journalism Studies. Advance online publication. https://doi.org/10.1080/1461670X. 2019.1566871

Pariser, E. (2011). The filter bubble: How the new personalized web is changing what we read and how we think. New York, NY: Penguin.

Peacock, C., Hoewe, J., Panek, E., \& Willis, G. P. (2019). Hyperpartisan news use: Relationships with partisanship, traditional news use, and cognitive and affective involvement. Paper presented at the Annual Conference of the International Communication Association, Washington, D.C., USA. 
Prior, M. (2007). Post-broadcast democracy: How media choice increases inequality in political involvement and polarizes elections. New York, NY: Cambridge University Press.

Sears, D. O., \& Freedman, J. L. (1967). Selective exposure to information: A critical review. Public Opinion Quarterly, 31(2), 194-213. https://doi.org/10.1086/
267513

Stroud, N. J. (2011). Niche news: The politics of news choice. New York, NY: Oxford University Press.

Toff, B., \& Nielsen, R. K. (2018). “I just Google it”: Folk theories of distributed discovery. Journal of Communication, 68(3), 636-657. https://doi.org/10.1093/joc/ jqy009

\section{About the Authors}

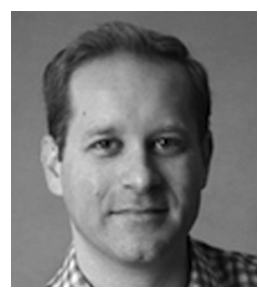

Matthew Barnidge (Ph.D., University of Wisconsin-Madison) is an Assistant Professor in the Department of Journalism \& Creative Media at The University of Alabama, where he directs the Emerging Media Research Group (@EMeRG_UA) and is a member of the Political Communication Research Group (@PolComResearch). He specializes in emerging news media and contentious political communication with an international perspective, and his work has been published in journals such as Political Communication, New Media \& Society, and Communication Research. Matthew is online at matthewbarnidge.com, and he tweets from @mbarni109.

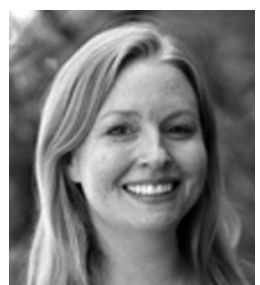

Cynthia Peacock (Ph.D., University of Texas at Austin) is an Assistant Professor in the Department of Communication Studies at The University of Alabama, where she leads the Political Communication Research Group (@PolComResearch). She is also a Faculty Research Associate with the Center for Media Engagement at the University of Texas at Austin. Cynthia teaches and researches in the area of political communication, and her work has appeared in journals such as Journalism, Social Media + Society, and American Behavioral Scientist. Learn more about her at cpeacock.people.ua.edu. 